\title{
Hydrocarbons as Alternate Refrigerants to Replace R134a in Domestic Refrigerators
}

\author{
Parashurama Siddegowda $^{1 *}$, Govindegowda Mundur Sannappagowda ${ }^{2}$, Vaibhav Jain ${ }^{3}$, Satheesh Javare Gowda ${ }^{4}$ \\ ${ }^{1}$ Mechanical Engineering Department, JSSATE, Bengaluru 560 060, India \\ ${ }^{2}$ Principal, Vivekananda college of Engineering and Technology, Puttur 574203, D.K, India \\ ${ }^{3}$ Mechanical\& Automation Engineering Department, MAIT, New Delhi 110086, India \\ ${ }^{4}$ Department of Mechanical Engineering, SJBIT, Bengaluru 560 060, India
}

Corresponding Author Email: parashurams@rediffmail.com

https://doi.org/10.18280/rcma.290204

Received: 15 January 2019

Accepted: 26 March 2019

\section{Keywords:}

COP, compressor work input, discharge temperature, displacement volume, volumetric efficiency

\begin{abstract}
The thermodynamic properties of hydrocarbons namely Propane, Cyclopropane, Propene, Methyl acetylene, Propadiene and Dimethyether as alternatives to replace R134a have been predicted using SRK EOS. The values of vapour pressure, liquid specific volume, vapour specific volume, liquid enthalpy, vapour enthalpy, liquid entropy, vapour entropy have been estimated over the temperature range from $-250^{\circ} \mathrm{C}$ to $+550^{\circ} \mathrm{C}$. Simulation of $89 \mathrm{~W}$ domestic refrigerator is carried out using ten state point vapour compression cycle. The theoretical performances of the hydrocarbons have been comparatively assessed using standard refrigeration parameters. According to our results, Propane, Propene are appropriate and recommended as alternatives of R134a with lower displacement compressor and Cyclopropane as direct substitute. Also implications with respect to material and lubricant oil compatibility, heat transfer characteristics are discussed.
\end{abstract}

\section{INTRODUCTION}

Refrigeration technology plays a significant role in safety and health of people especially the preservation of food and lifesaving drugs. Refrigeration technology is also applied to provide comfort through air conditioning systems and for industrial processes. Knowing the $\mathrm{CFC}$ hazard and regulations from Montreal and Kyoto protocols one has to consider Generation-3 refrigerants -HCs \& Natural refrigerants. When applied to the Refrigerator sector CFC-12 is outdated and has been substituted by the intermediate refrigerant HFC-134a (Generation-2). However, by 2020 the Generation-2 refrigerants must also be phased out; in this context, prospects of Generation-3 refrigerants need to be analysed and the existing HFC-134a refrigerator inventories need to be retrofit or replaced.

Many works have been done in order to develop alternative refrigerants to R12 in accordance with Montreal and Kyoto protocols. R152a [1-2] is an excellent alternative and compatible with mineral oils. Its pressure level discourages its use as a substitute of R12.Ammonia [3-4] is one of the refrigerants in the field of refrigeration especially for very low temperatures but it is toxic. Interaction coefficients for binary mixtures R12/R152a, R134a/R134 and R22/F152a have been calculated by J.R Sand et al. [5]

Propane is [6] an attractive alternative regarding its COP, its compatibility with mineral oil, its low cost, availability and its negligible GWP. Concerning the research of new fluids, the majority of previous results [1, 7-12] show that $\mathrm{R} 134 \mathrm{a}$ is the best possible substitute of R12.It has zero ODP but it is global warming gas, not miscible with mineral oil, its energy efficiency is slightly lower and poor heat transfer at low temperatures. Jung et al. [13] performed a computer simulation of domestic refrigerator charged with many pure and mixture as possible alternatives of R12 and studied experimentally R290/ R600a (60/40) and obtained $2.45 \%$ increase in energy efficiency compared to R12. The predicted properties are not reliable as only NBP and structural details are used in the development of properties. Somchai Wongwises et al. [14] have determined the performance of vapour compression system with Propane, HC, HFC mixtures and recommended $\mathrm{R} 290 / \mathrm{R} 600 \mathrm{a} / \mathrm{R} 14 \mathrm{a}$ (40/30/30) as alternative from energy point of view. Tashtoush et al. [15] investigated experimentally ternary mixture of butane /propane/ R134a (43.91/33.31/22.78) and the obtained performance was higher than that of R12. Sekhar et al. [16] suggested R134a/R600a/R290 as a retrofit mixture for R12 systems and obtained 4.1-7.6\% energy savings compared to R12. Kuijipers et al. [17] have investigated experimentally HFC 152a, DME, HC270 and HC290/R600a (21/79) and concluded that the performance of R152a, R270 and R290/R600a (21/79) was found to be slightly higher than that of DME. Eric Granryd [18] analysed Hydrocarbons theoretically and concluded that Hydrocarbons are the better substitutes of R12. Saleh et al. [19] developed properties of candidate refrigerants as alternatives to R12 using Back one equation of state, did thermodynamic analysis and concluded that $\mathrm{RE} 170, \mathrm{R} 152 \mathrm{a}$ and $\mathrm{RC} 270$ are promising refrigerants to replace $\mathrm{R} 12$.

The problem in case of mixtures is that there is uncertainty of their thermodynamic and thermo physical properties and also in case of leakage it becomes very critical that the performance of the refrigeration system changes. Hydrocarbon refrigerants have zero ODP, negligible GWP and are compatible with commonly used mineral oil. The main drawback of these refrigerants is that they are highly flammable. Hydrocarbons, in comparison to R12 have high latent heat of vaporization and low value of density make these 
refrigerants attractive in spite of their flammability by virtue of low charge. In the present study theoretical analysis is undertaken to ascertain the necessary modifications to be incorporated in the system for each of the refrigerants R290, R270, R170, R1270, R2250, R2250b and DME making necessary modifications in the same system as is used for R134a to achieve the same capacity viz. $89 \mathrm{~W}$ evaporator and comparable performance with that of R134a thus making the system environmental friendly.

All Hydrocarbons except Propyne and Propadiene are compatible with Copper. Propyne and Propadiene react with Copper forming metal acetylides which are explosive in nature [20]. Hence Propyne and Propadiene require change in the material of construction of the refrigerator. All hydrocarbons are miscible with conventional mineral oil and have excellent lubrication properties. Another advantage of Hydrocarbons is that because of positive evaporator pressure, there is no entry of moist air into the system. Studies by Mathur and Jung [21] on heat transfer characteristics of alternate refrigerants indicate that heat transfer coefficients for Hydrocarbons are significantly higher than R12 both in liquid and gaseous phase. Hence, Hydrocarbons are viable candidates from view point of heat transfer. Parashurama et al. [22] in his previous work predicted thermodynamic properties of HFCs and Fluroethers using SRK EOS, screened and suggested R152a and R161 as alternatives to R134a. Also developed thermodynamic properties of HFCs and HCs using SRK EOS and PSRK mixing rule and recommended several binary mixtures as short term and long term alternatives of R134a [23].

\section{MODELLING OF THERMODYNAMIC PROPERTIES}

The thermodynamic properties of refrigerants are required to calculate system performance. The basic properties of hydrocarbons were reported by Reid et al. [24] and Calm and Hourahan, [25] and Jung, [26]. Table 1 lists the values of property data at design conditions for R134a and candidate refrigerants. The thermodynamic properties required for simulation are modeled using S-R-K equation of state. The roots of the cubic equation for specific volume in liquid and gaseous phases are solved using Cardon's method. Thermodynamic properties such as liquid enthalpy vapour enthalpy, liquid entropy, vapour entropy have been calculated over a range of temperatures using enthalpy and entropy departure functions using the procedure given in Appendix. The reference state of the refrigerants is taken to be having saturated liquid enthalpy and saturated liquid entropy of 200 $\mathrm{kJ} / \mathrm{kg}$ and $1 \mathrm{~kJ} / \mathrm{kgK}$ at $0{ }^{\circ} \mathrm{C}$ respectively. A C-program was developed to obtain thermodynamic properties at any temperature $\mathrm{T}$ and pressure $\mathrm{P}$. The inputs to the program are NBP, critical temperature, critical pressure, molecular weight and Wagner constants. The saturated and superheated properties are displayed in separate output files over the range mentioned by the user. The vapor pressure data (Wagner constants) and Zero pressure specific heat data for the refrigerants are taken from reference [24]. The developed Thermodynamic properties are validated for R12 and are in good agreement with ASHRAE [27] values with acceptable error. These developed properties are then used in the evaluation of cycle performance of the system.

Table 1. Basic properties of R134a and candidate refrigerants

\begin{tabular}{cccccccc}
\hline Refrigerant & $\mathbf{M}(\mathbf{k g} / \mathbf{k g} \mathbf{~ m o l})$ & $\mathbf{N B P}\left({ }^{\circ} \mathbf{C}\right)$ & $\mathbf{v}_{\mathbf{1}}\left(\mathbf{m}^{\mathbf{3}} \mathbf{\mathbf { k g }}\right)$ & $\mathbf{h}_{\mathbf{f g}}(\mathbf{k J} / \mathbf{K g})$ & $\mathbf{T}_{\mathbf{c}}\left({ }^{\circ} \mathbf{C}\right)$ & $\mathbf{P}_{\mathbf{c}}(\mathbf{b a r})$ & $\boldsymbol{\omega}$ \\
\hline R134a & 102.03 & -26.1 & 0.2593 & 221.83 & 374.25 & 40.6 & 0.327 \\
R12 & 120.91 & -27.95 & 0.2373 & 165.13 & 385 & 41.4 & 0.204 \\
R290 & 44.094 & -42.07 & 0.2968 & 409.63 & 369.8 & 42.5 & 0.153 \\
R1270 & 42.081 & -47.65 & 0.2482 & 415.13 & 364.9 & 46.0 & 0.144 \\
R270 & 42.081 & -32.85 & 0.5033 & 466.47 & 397.8 & 54.9 & 0.130 \\
DME & 46.069 & -24.85 & 0.7929 & 466.6 & 400 & 52.4 & 0.200 \\
R2250 & 40.065 & -34.45 & 0.5155 & 441.56 & 393 & 54.7 & 0.313 \\
R2250b & 40.065 & -23.25 & 0.9324 & 565.15 & 402.4 & 56.3 & 0.215 \\
\hline
\end{tabular}

\section{THEORETICAL THERMODYNAMIC ANALYSIS}

A ten point cycle is used for thermodynamic analysis is shown in Figure 1. The ten state points as shown in Figure 1 corresponds to the conditions given below.

(1). Super-heated refrigerant vapour after pressure drop at suction valve

(2). High pressure high temperature refrigerant vapour after isentropic compression

(3). High pressure refrigerant leaving compressor

(4). Refrigerant in saturated vapor state in the condenser at $55^{\circ} \mathrm{C}$

(5). Refrigerant in saturated liquid state in the condenser at $55^{\circ} \mathrm{C}$

(6). Sub cooled liquid refrigerant leaving condenser at $43^{\circ} \mathrm{C}$

(7). High pressure sub cooled liquid entering capillary tube at $32{ }^{\circ} \mathrm{C}$

(8). Wet mixture leaving Capillary tube at $-25{ }^{\circ} \mathrm{C}$

(9). Refrigerant in saturated vapor state in evaporator
(10). Superheated vapour leaving and entering compressor Pressure drops at inlet and outlet valves of compressor are assumed as follows: [28]

(1) For R290 and other Hydrocarbons $\Delta \mathrm{P}_{\mathrm{i}}=0.2$ and $\Delta \mathrm{P}_{\mathrm{o}}$ $=0.4$ bar.

(2) For R12, $\Delta \mathrm{P}_{\mathrm{i}}=0.1 \& \Delta \mathrm{P}_{\mathrm{o}}=0.25$ bar.

Evaporator Pressure drop is 0.1 bar \& ambient temperature is $43{ }^{\circ} \mathrm{C}$.

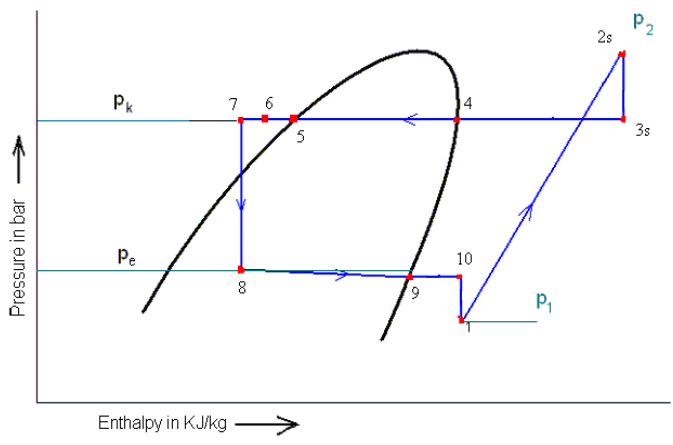

Figure 1. Ten point Vapour compression cycle 


\section{EVALUATION OF PERFORMANCE PARAMETERS}

Performance parameters for candidate refrigerants to obtain the same cooling capacity of $89 \mathrm{~W}$ as that of R134a are calculated and listed in Table 2. When compressor designed for R12 refrigerant is used with alternate |refrigerants viz., hydrocarbons the volumetric efficiency will be affected. It is essential to have an expression which predicts the volumetric efficiency of the compressor matching with experimental performance. A modified expression adopted in this work, has been derived to estimate the volumetric efficiency of the alternate refrigerants especially the Hydrocarbons whose specific heats are much higher compared to CFCs and HFCs.

$$
\eta_{\mathrm{v}}=K\left[1-\left(\mathrm{C}\left(\frac{\mathrm{P}_{2}}{\mathrm{P}_{1}}\right)^{1 / \mathrm{n}}-1\right)\right]
$$

The constant $\mathrm{K}$ is introduced to take care of change in the state of the suction vapor from $\mathrm{T}_{10}, \mathrm{P}_{10}$ to $\mathrm{T}_{1}, \mathrm{P}_{1}$ resulting from pressure drop at suction valve, $\&$ heat gain during cooling of windings and heat exchange with cylinder walls, and also change in the state of the discharge vapor from $T_{2}, P_{2}$ to $T_{3}, P_{3}$ due to pressure drop at delivery valve, heat loss to cylinder

walls and the leakage across the piston rings.

$$
\begin{gathered}
\text { Pressure ratio, } P=\frac{\mathrm{P}_{2}}{\mathrm{P}_{1}} \\
\text { Refrigerating effect, } q_{0}=\left(h_{9}-h_{8}\right) \\
\dot{m}=\frac{Q_{0}}{q_{0}} \\
V_{p}=\frac{m v_{1}}{\eta_{v} 60 N} \\
Q_{k}=\dot{m}\left(h_{3 s}-h_{6}\right) \\
C O P=\frac{Q_{0}}{W_{i s}} \\
\mathrm{~W}_{\mathrm{is}}=\dot{m}\left(h_{2 s}-h_{1}\right) \\
T_{s t g}=\frac{V_{p}\left(P_{2}-P_{1}\right)}{2}
\end{gathered}
$$

Table 2. Performance parameters of R134a and alternatives for $\mathrm{Te}=-25{ }^{\circ} \mathrm{C} \& \mathrm{Tk}=55{ }^{\circ} \mathrm{C}$

\begin{tabular}{ccccccccccc}
\hline Refrigerant & $\begin{array}{c}\mathbf{m} \times \mathbf{1 0}^{\mathbf{3}} \\
(\mathbf{k g} / \mathbf{s})\end{array}$ & $\mathbf{P}_{\mathbf{r}}$ & $\begin{array}{c}\mathbf{T}_{\mathbf{2}} \mathbf{S} \\
\left({ }^{\circ} \mathbf{C}\right)\end{array}$ & $\mathbf{W}_{\text {is }}(\mathbf{W})$ & $\mathbf{C O P}$ & $\begin{array}{c}\mathbf{V}_{\mathbf{p}} \\
(\mathbf{c c})\end{array}$ & $\boldsymbol{\gamma}$ & $\eta_{\mathbf{v}}(\mathbf{\%})$ & $\begin{array}{c}\mathbf{Q}_{\mathbf{k}} \\
(\mathbf{W})\end{array}$ & $\begin{array}{c}\mathbf{T}_{\text {stg }} \\
(\mathbf{N m})\end{array}$ \\
\hline R134a & 0.597 & 17.641 & 125 & 45.58 & 1.9102 & 5.83 & 1.102 & 0.608 & 113 & 4.17 \\
R 12 & 0.722 & 0.99 & 139.1 & 43.94 & .026 & 4.6 & 1.137 & 0.756 & 136.23 & 2.77 \\
R 290 & 0.289 & 9.37 & 120.8 & 40.62 & 2.198 & 2.4 & 1.124 & 0.735 & 133.85 & 2.06 \\
R 1270 & 0.281 & 8.93 & 133.3 & 41.1 & 2.168 & 1.9 & 1.146 & 0.760 & 133.98 & 1.92 \\
R 270 & 0.240 & 10.22 & 146.5 & 40.68 & 2.189 & 3.47 & 1.151 & 0.719 & 132.40 & 2.25 \\
DME & 0.240 & 12.63 & 150.0 & 46.43 & 1.919 & 6.85 & 1.139 & 0.634 & 137.16 & 4.02 \\
R 2250 & 0.242 & 7.13 & 98.76 & 33.06 & 2.692 & 3.28 & 1.106 & 0.788 & 128.65 & 1.46 \\
R 2250b & 0.218 & 13.85 & 149.3 & 39.69 & 2.239 & 5.30 & 1.102 & 0.608 & 151.90 & 4.28 \\
\hline
\end{tabular}

\section{RESULTS AND DISCUSSION}

The estimated values are used in the evaluation of the cycle performance of the system. To confirm the reliability of SRK equation of state volumetric and thermodynamic properties of R12 have been calculated and validated with experimental data from ASHRAE [23]. The estimated values are within $1 \%$ maximum error for vapour specific volume, for enthalpies within $10 \%$ and $8 \%$ for entropies over temperature range of $25{ }^{\circ} \mathrm{C}$ to $+55^{\circ} \mathrm{C}$. The uncertainties in liquid specific volume, enthalpies and entropies are due to imperfect estimation of specific heat and liquid specific volume. Experimental studies of these parameters need to be carried out to get better estimates of thermodynamic data. Different parameters of refrigerants are calculated using Equations (1) to (9) and are compared with R134a.For tropical countries like India, the usual design conditions for refrigerators are $\mathrm{T}_{\mathrm{e}}=-25{ }^{\circ} \mathrm{C}$ and $\mathrm{T}_{\mathrm{k}}=55^{\circ} \mathrm{C}$. Table 2 lists the values of performance parameters for R134a and alternatives. The variation of Performance parameters with evaporator temperature are plotted as seen from Figure 2 to 5. Discussion of the results is given in turn as follows.

\section{Pressure ratio}

As can be seen from Table 2, the values of Pressure ratio of all refrigerants appear to be lower;

this implicates the requirement of lower displacement compressor. The values of Pressure ratio decrease with increase in evaporator temperature as shown in Figure 2.

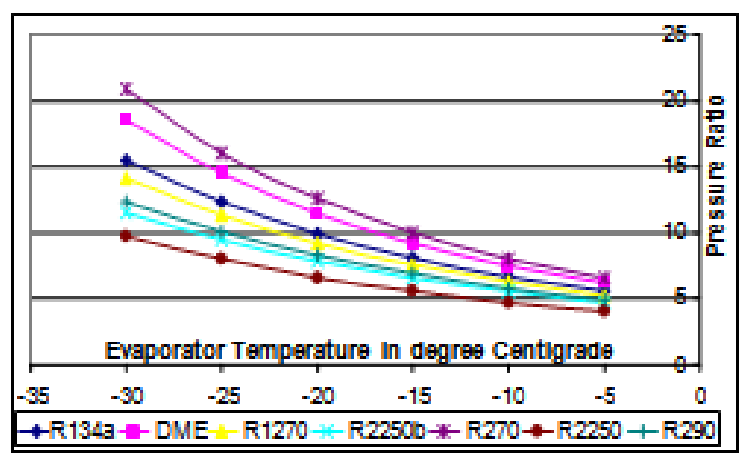

Figure 2. Variation of pressure ratio with evaporator temperature 


\subsection{Coefficient of performance}

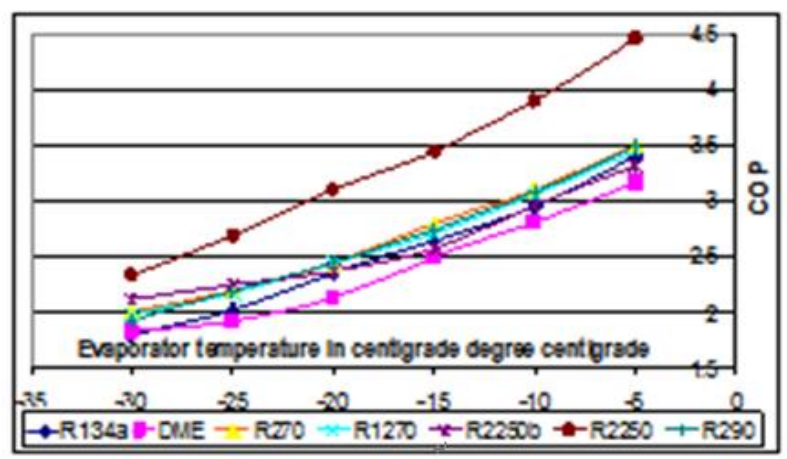

Figure 3. Variation of COP with evaporator temperature

\subsection{Rating of motor}

Table 2 lists the rating of the motor for all the refrigerants for evaporator capacity of $89 \mathrm{~W}$. It can be observed that the lower boiling refrigerant DME demands higher rated motor. The higher boiling refrigerants R2250, R2250b, R290 and R1270 require lower rating of the motor than that of R134a. This implicates that the energy consumption is slightly higher in case of DME and lower for other candidate refrigerants. The energy consumption increases with decrease in evaporator temperature as shown in Figure 4.

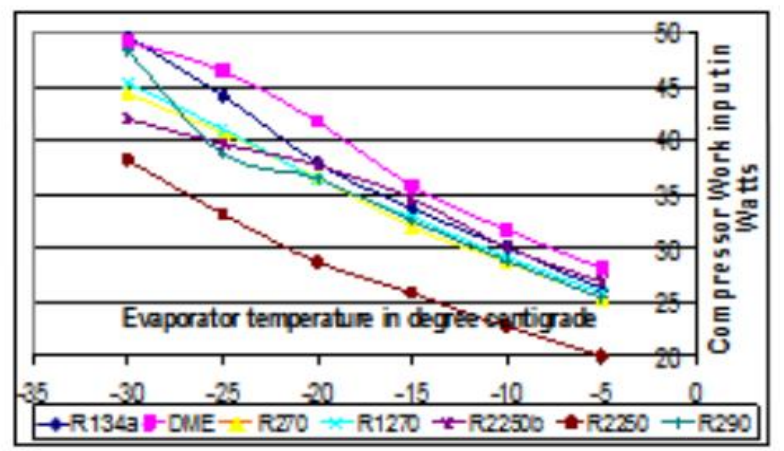

Figure 4. Variation of compressor work input with evaporator temperature

\subsection{Volumetric efficiency}

From Table 2, it can be observed that the values of volumetric efficiencies of the refrigerants are higher than that of $\mathrm{R} 134 \mathrm{a}$ and decreases with decrease in evaporator temperature as seen from Figure 5. For R 2250b the value of volumetric efficiency is same as that of R134a.

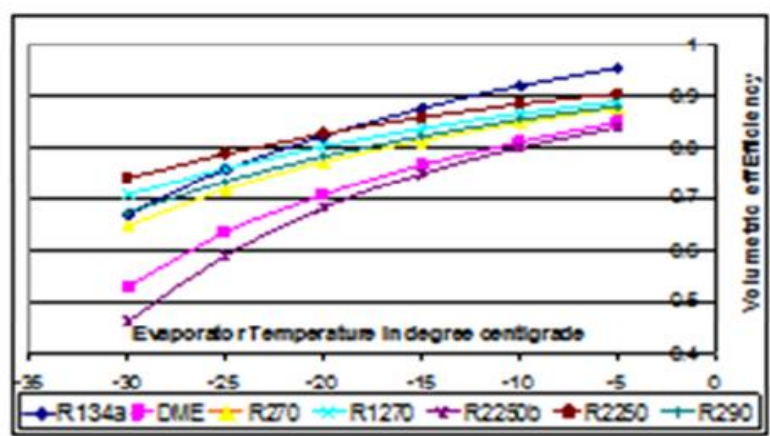

Figure 5. Variation of volumetric efficiency with evaporator temperature

\section{CONCLUSION}

The performance of all proposed Hydrocarbons is higher than that of R134a. R270 can be used as direct substitute. Refrigerants R290, R1270 are recommended as alternatives to R134a with lower displacement compressor. DME can be used with higher compressor displacement. Due to lower mass flow rates the design of evaporator for R290, R1270, R270 has to be changed slightly i.e., the evaporator pipes have to be constructed of smaller diameter pipes and also due to lower mass flow rates smaller bore and longer capillary than that used for R134a is to be used for efficient throttling. The existing R12 Compressors fitted with 75 litres Refrigerators have lower displacement compressors can be used for hydrocarbon refrigerants from the point of view of power savings. Refrigerants R2250 and R2250b although thermodynamic ally attractive cannot be used as alternatives as they are explosive in nature and not compatible with materials of construction.

\section{REFERENCES}

[1] Kuijpers, L., Miner, S.M. (1988). The CFC issue and the CFC -Forum. Proceedings of I.I.R meeting, Perdue, 291304.

[2] Banasal, P.K., Dutto, T., Hivet, B. (1992). Performance evaluation of environmentally benign refrigerants in heat pumps 1: A simulation study. International Journal of Refrigeration, 15(6): 349-356. https://doi.org/10.1016/0140-7007(92)90017-O

[3] Bougard, J. (1990). Overview of substitutes for CFCs in compression systems. Proc.of Int.Colloq.of Brussels, 6668.

[4] Lorentzen, G. (1988). Ammonia:an excellent alternative. Procs of I.I.R meeting, Perdue, 291-304.

[5] Sand, J.R., Fischer, S.T., Jones, J.K. (1994) Interaction coefficients for several binary mixtures of ozone safe Refrigerants. International Journal of Refrigeration, 17(2): 123-129. https://doi.org/10.1016/0140-7007(94)90053-1

[6] James, R.W., Missenden, J.F. (1992). Use of propane for domestic refrigerators. International Journal of Refrigeration, $\quad 15(2)$ : 95-100. https://doi.org/10.1016/0140-7007(92)90033-Q

[7] Preisegger, E., Henrici, R. (1992). Refrigerant 134a: The first step into a new age of refrigerants. International Journal of Refrigeration, 15(6): 326-331. https://doi.org/10.1016/0140-7007(92)90014-L

[8] Spauschus, H.O. (1988). HFC134a as a substitute refrigerant for CFC12. Proc.of I.I.R Meeting, Perdue.

[9] Devotta, S., Gopichand, S. (1992). Comparative assessment of HFC 134a and some refrigerants as alternatives to R12. International Journal of Refrigeration, $\quad 15(2)$ : $112-118$. https://doi.org/10.1016/0140-7007(92)90035-S

[10] Carpenter, N.E. (1992). Retrofitting R134a into existing CFC12 systems. International Journal of Refrigeration 15(6): 332-339. https://doi.org/10.1016/01407007(92)90015-M

[11] Atwood, T. (1988). CFCs in transition. International Journal of Refrigeration, 11(4): 234-238. https://doi.org/10.1016/0140-7007(88)90079-5 
[12] Pannock, J., Radermacher, R., Liu, Z., Yu, K. (1994). Evaluation of R134a and R152a as working fluids in a Domestic Refrigerator/ Freezer. ASHRAE Transactions, USA.

[13] Jung, D., Kim, C.B., Song, K., Park, B. (2000). Testing of Propane/isobutene mixture in domestic refrigerators. International Journal of Refrigeration, 23(7): 517-527. https://doi.org/10.1016/S0140-7007(99)00084-5

[14] Wongwises, S., Chimre, N. (2005). Experimental study of hydrocarbon mixtures to replace HFC-134a in a domestic refrigerator. Energy Conversion and Management, $\quad 46(1)$ : $\quad 85-100$. https://doi.org/10.1016/j.enconman.2004.02.011

[15] Tashtoush, B., Tahat, M., Shudeifat, M.A. (2002). Experimental study of new refrigerant mixtures to replace R12 in domestic refrigerators. Applied Thermal Engineering, 22(5): 495-506. https://doi.org/10.1016/S1359-4311(01)00107-7

[16] Sekhar, S.J., Lal, D.M. (2005). $\mathrm{HFC} 134 \mathrm{a} / \mathrm{HC} 600 \mathrm{a} / \mathrm{HC} 290$ mixture a retrofit for $\mathrm{CFC} 12$ systems. International Journal of Refrigeration, 28(5): 735-743. https://doi.org/10.1016/j.ijrefrig.2004.12.005

[17] Kuijpers, L.J.M., De Wit, J.A, Janssen, M.J.P. (1988). Possibilities for the replacement of CFC12 in domestic equipment. International Journal of Refrigeration, 11(4): 284-291. https://doi.org/10.1016/0140-7007(88)90088-6

[18] Granryd, E. (2001). Hydrocarbons as refrigerants-an overview. International Journal of Refrigeration, 24(1): 15-24. https://doi.org/10.1016/S0140-7007(00)00065-7

[19] Saleh, B., Wendland, M. (2006). Screening of pure fluids as alternative refrigerants. International journal of $\begin{array}{ll}\text { Refrigeration, } & 29(2):\end{array}$ https://doi.org/10.1016/j.ijrefrig.2005.05.009

[20] Kyser, E.A. (1995). Precision total pressure measurements of propyne with propane, propene, and propadiene. J. Chem. Eng. Data, 40(4): 756-764. https://doi.org/10.1021/je00020a007

[21] Mathur, G.D. (1998). Heat transfer coefficients for propane, isobutane and 50/50 mixture of propane and isobutane. ASHRAE Transactions USA.

[22] Parashurama, S., Ramesha, D.K., Govindegowda, M.S. (2019). Screening of HFCs and fluoroethers as alternatives to R134a using SRK EoS. Journal of the Institution of Engineers (India): Series C, 1-7. https://doi.org/10.1007/s40032-019-00501-5

[23] Siddegowda, P. (2018). Development of alternative binary mixtures to replace HFC 134a in domestic refrigerator. Chemical Engineering Transactions, Adic.

[24] Reid, R., Prausnitz, J.M., Poling, J.M. (1987). The properties of gases and liquids. $4^{\text {th }}$ edition, Mc.Graw Hill, New York.

[25] Calm, J.M., Hourahan, G.C. (2001). Refrigerant data summary. Engineered Systems, 18(11): 74-88.

[26] Jung, D. (2000). Testing of propane/isobutene mixture in domestic refrigerators. International Journal of Refrigeration,

https://doi.org/10.1016/S0140-7007(99)00084-5

[27] ASHRAE Handbook of Fundamentals. (1989). ASHRAE, Atalanta, USA.

[28] Babu, A.T.P. (1997). Theoretical and experimental investigation of alternatives to $\mathrm{CFC} 12$ in refrigerators. Ph.D Dissertation. Indian Institute of Technology, New Delhi, India.

\section{NOMENCLATURE}

$\mathrm{C}$

COP

$\mathrm{h}$

M

$\dot{\mathrm{m}}$

$\mathrm{n}$

$\mathrm{P}$

$\mathrm{Q}_{0}$

$\mathrm{T}$

$\mathrm{V}$

W

\section{Abbreviations}

$\mathrm{N}$

NBP

CFC

DME

EOS

GWP

$\mathrm{HCs}$

HFCs

HCFCs

ODP

SRK

\section{Greek symbols}

$\eta$

$\mu$

\section{Subscripts}

\section{c}

fg

i

is

$\mathrm{k}$

n

o

$0,1,2$ etc.
Clearancefactor, Specific heat, $\mathrm{kJ} / \mathrm{kg}^{\circ} \mathrm{C}$

Coefficient of Performance

Enthalpy, kJ/kg

Molecular weight, $\mathrm{kg} / \mathrm{kgmol}$

Mass flow rate, $\mathrm{kg} / \mathrm{s}$

Polytropic index

Pressure, bar

Refrigerating Effect, KW

Temperature, $\mathrm{K}$ and Torque, $\mathrm{N}-\mathrm{m}$

Specific Volume, $\mathrm{m}^{3} / \mathrm{kg}$

Power input, W

RPM of the compressor

Normal Boiling point, ${ }^{\circ} \mathrm{C}$

Chlorofluorocarbons

Dimethyl ether

Equation of state

Global Warming Potential

Hydrocarbons

Hydrofluorocarbons

Hydrochlorofluorocarbons

Ozone Depletion Potential

Soave-Redlick-Kong

Specific Heat ratio

Efficiency

dynamic viscosity, $\mathrm{kg} \cdot \mathrm{m}^{-1} \cdot \mathrm{s}^{-1}$

Critical

Vaporization

Inlet

Isentropic

Condenser

Polytropic

Starting Torque

State Points

Volumetric Efficiency 